\title{
Preparation of Waste GFRP Fiber Reinforced Gypsum Block with Water-resistant and Energy Storage Characteristics
}

\author{
Meng-Meng Zhang ${ }^{1}$, Xiong-mu Chen ${ }^{2}$ and Feng-Qing Zhao ${ }^{1}$ \\ ${ }^{1}$ Department of Chemical Engineering, Hebei University of Science \& Technology, Shijiazhuang, 050018, China \\ ${ }^{2}$ Hebei Engineering Research Center of Solid Waste Utilization, Shijiazhuang, 050018, China
}

\begin{abstract}
Gypsum block possesses good performances such as volume stability, lightweight and thermal insulation, is recognized as typical eco-friendly building material. However, its poor water resistance characteristics restrict the application. The semi-hydrated desulphurization gypsum is modified with steel slag, granulated blast-furnace and carbide slag (SGC) composite powder as well as waste glass-reinforced plastic (GFRP) fiber, aiming at producing water-resistant gypsum block. The proper mass proportioning of the modified gypsum block is obtained: semi-hydrated desulphurization gypsum $75 \%$, SGC $25 \%$ and waste GFRP fiber $1.0 \%$. The product is of softening coefficient of 0.84 and thermal flexural strength of 8.6 MPa. Phase change energy storage material (PCM) is used to increase the energy saving characteristics of the block. Compared with ordinary gypsum walls, the modified gypsum block with CA-SA exhibits good energy storage property.
\end{abstract}

\section{Introduction}

The development of low-energy wall materials is the main approach to meet the need of energy saving. Gypsum block is a typical eco-type and energy-saving material. Excellent properties, such as volume stability, lightweight and thermal insulation, have made it popular theses years. But its poor water resistance and low mechanical strength restrict the application.

There are various ways to increase the strength and water resistance properties of gypsum block by addition of water-proofing agent, as organic materials, inorganic materials or the both. But the traditional organic water-proofing agents have some negative impacts on mechanical strength of gypsum block. The inorganic materials used are mostly cement or/and industrial wastes, which seems not so satisfactory [1,2]. Much research has done to increase water-resistance and mechanical strength for gypsum block by using super-plasticizer and $\alpha$-hemihydrate gypsum, and obtained some positive results [3]. The mechanical strength of gypsum block can also be reinforced by fiberglass, plant fibers, synthetic fibers $[4,5]$. However, high cost of raw materials limits their application.

In this paper, semi-hydrated desulphurization gypsum was modified with SGC powder and waste glass-reinforced plastic fiber, aiming at increasing the water resistance and mechanical strength. In addition, phase change energy storage material is used in gypsum block for being energy saving characteristics.

\footnotetext{
${ }^{\text {a }}$ Corresponding author: zhaofq3366@126.com
} 


\section{Materials and methods}

\subsection{Raw materials}

The desulfurization gypsum used in this work was provided by China Xibaipo Power Plant; steel slag and granulated blast-furnace slag from Shijiazhuang Iron and Steel Co. Ltd.; carbide slag from Shijiazhuang Chemical fiber Co. Ltd; waste glass-reinforced plastic fiber from Jizhou Mechanical Technology Co. Ltd. The waste mycelium used was from Huabei Pharmaceutical Co. Ltd, which used to prepare gypsum retarder (WPM retarder) in laboratory [6,7]. Phase change energy storage materials were bought from market. The compositions of main raw materials are listed in Table 1.

Table 1. Principal composition of raw materials, wt $\%$

\begin{tabular}{cccccccccc}
\hline Composition & $\mathrm{CaO}$ & $\mathrm{SiO}_{2}$ & $\mathrm{FeO}$ & $\mathrm{Fe}_{2} \mathrm{O}_{3}$ & $\mathrm{MgO}$ & $\mathrm{Al}_{2} \mathrm{O}_{3}$ & $\mathrm{MnO}$ & $\mathrm{f}-\mathrm{CaO}$ & $\mathrm{SO}_{3}$ \\
\hline Desulfurization gypsum & 37.76 & 1.38 & 0.32 & 0.16 & 0.27 & & & 50.34 \\
Waste glass-reinforced plastic & 27.23 & 55.12 & & 2.202 & 1.33 & 8.94 & & & \\
Steel slag & 36.35 & 15.33 & 9.27 & 12.7 & 5.51 & 8.49 & 5.51 & 4.82 & \\
Granulated blast-furnace slag & 34.15 & 41.20 & & 13.66 & 8.47 & 0.84 & 1.11 & & \\
Carbide slag & 92.02 & 3.82 & 0.50 & 0.14 & 2.72 & & & 0.63 \\
\hline
\end{tabular}

\subsection{Methods}

The mixture of steel slag and granulated blast-furnace slag was ground to desired fineness, mixed with carbide slag, forming SGC composite powder, which is used to improve mechanical strength and water-resistant characteristics of modified gypsum block. PCM is added to the mixture to obtain energy storage characteristics. Specimens with dimension of $40 \mathrm{~mm} \times 40 \mathrm{~mm} \times 160 \mathrm{~mm}$ were molded, then de-molded after 2 hours, and cured at desired conditions. The flexural strength value was the average of every three tests, whereas the compressive strength value was the average of every six tests.

For measurement of the fineness of blast-furnace slag powder and steel slag powder, $45 \mu \mathrm{m}$ sieve residue and Blaine values were used. Fig. 1 gives the flow-sheet of the preparation of gypsum block.

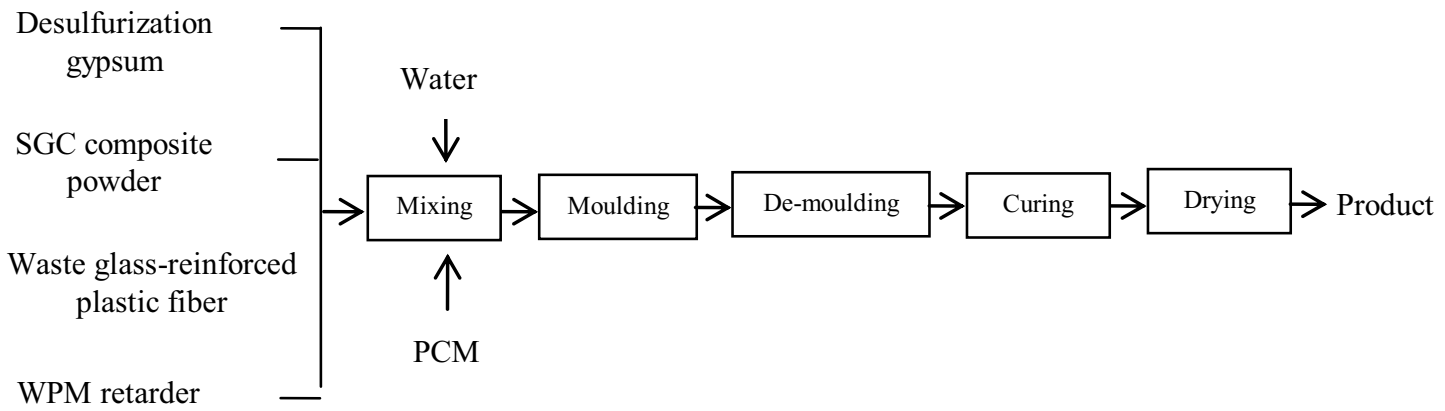

Figure 1. Preparation of water-resistant gypsum block with energy storage characteristics

\section{Results and Discussion}

\subsection{Effect of SGC composite powder on water resistance}


The semi-hydrated desulphurization gypsum is modified with SGC composite powder which is used to improve water resistant property. Here, the optimal mass ratio of steel slag: granulated blast-furnace slag: carbide slag is 50:50:0.08, according to initial experiments.

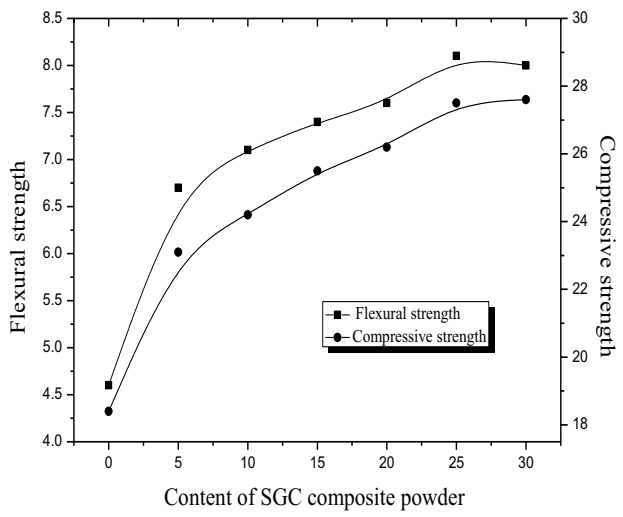

Figure 2. Effect of SGC powder on the mechanical strength

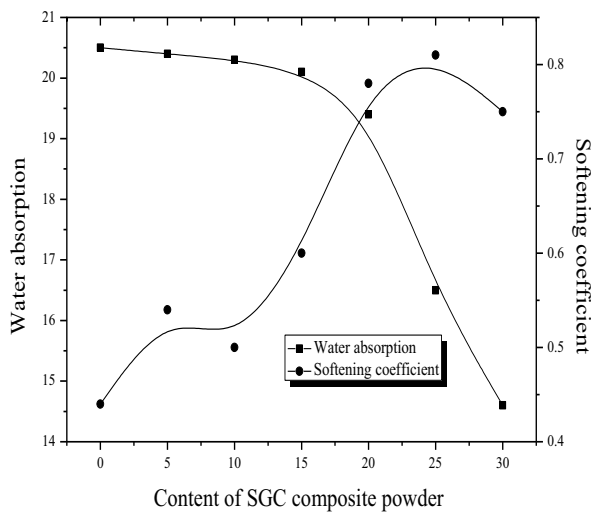

Figure 3. Effect of SGC powder on water resistance

We can see from Fig. 2 that the mechanical strength increases with the addition of SGC, and reaches peak vale when the content of SGC composite powder is $25 \%$. Fig. 3 shows that with the increase of the content of SGC composite powder, the water absorption decreases sharply. However, the softening coefficient of gypsum block with SGC composite powder is improved, and reaches highest value of 0.81 when the content of SGC powder is around $25 \%$. The results show SGC powder have significant effect on the mechanical strength and water resistance of the gypsum block. Steel slag and granulated blast-furnace slag have high content of glass phase, thus possess high potential hydration activity. Carbide slag as alkali activator can enhance remarkably the activity of steel slag and granulated blast-furnace slag. The hydration products are formed such as ettringite and hydrated calcium silicate, and the strength and water-resistance of the gypsum block are increased accordingly.

\subsection{Effect of waste glass-reinforced plastic fiber on water resistance}

The influence of waste glass-reinforced plastic fiber with different length and addition on flexural strength and water-resistance of the gypsum block were investigated

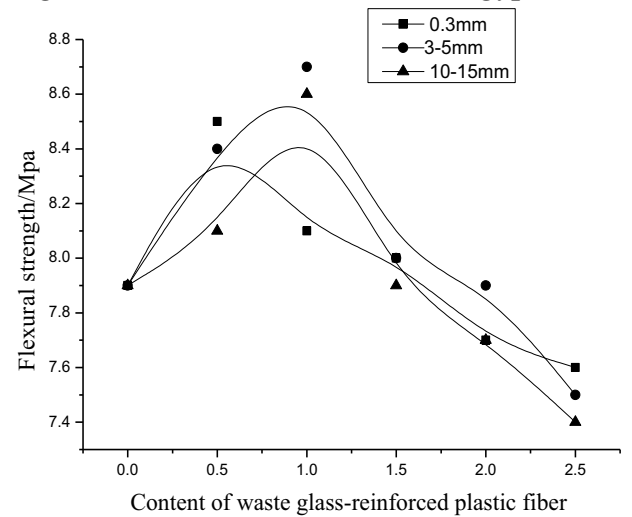

Figure 4. Effect of WGFP fiber on flexural strength of test block

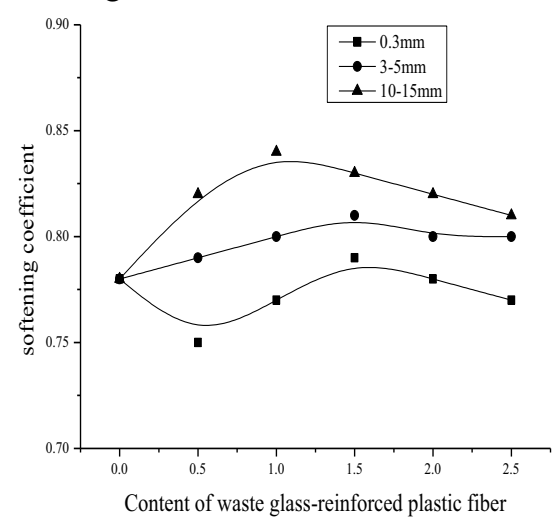

Figure 5. Effect of WGFP fiber on softening coefficient of test block 
From Fig. 4 we can see that when the waste glass-reinforced plastic fiber is in the range from $0 \%$ to $1 \%$, the flexural strength of gypsum block increases. Fig. 4 and Fig. 5 show that $10-15 \mathrm{~mm}$ fiber was more suitable for the flexural strength and softening coefficient of gypsum block than shorter fibers. Excessive fiber results in the decrease in mechanical strength of the block.

\subsection{Overall modification effect of WGFP fiber on gypsum block}

Based on above study, we come to the conclusion that both SGC powder and WGFP fiber have positive effect on the mechanical strength and water-resistance property of gypsum block. The results were obtained for the modifier: SGC composite powder $25 \%$, WGFP fiber $1.0 \%$ (fiber length is $10-15 \mathrm{~mm})$. On this basis, the performance of gypsum block is tested: softening coefficient of 0.84 , compressive strength of $27.5 \mathrm{MPa}$ and flexural strength of 8.6 MPa. Fig. 6 gives the fracture and cross section of the modified gypsum block. It was shown that the gypsum samples containing WGFP fiber can weaken or eliminate the tensile stress of crack, restraining the extension, which increase the flexural strength of the block.
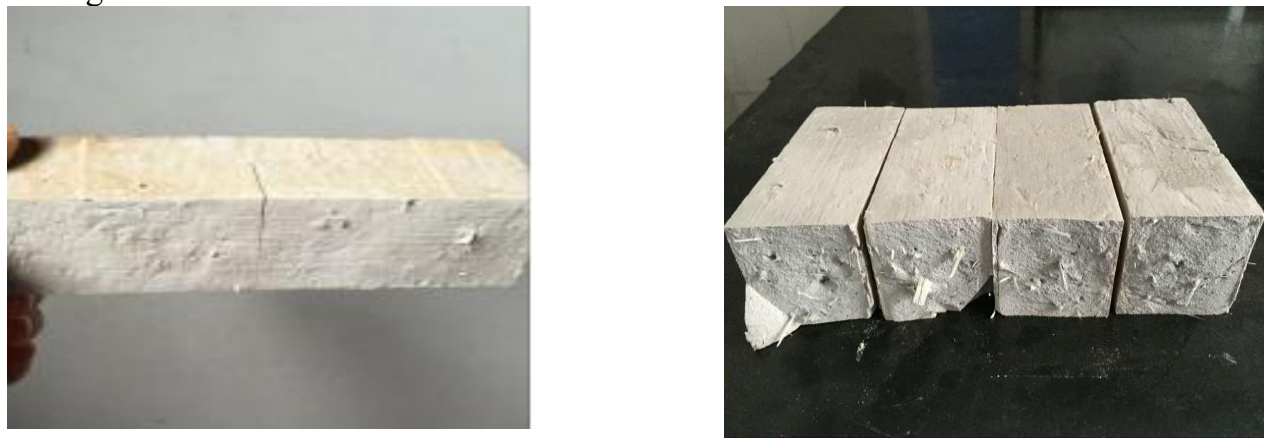

Figure 6. Fracture and cross section of the modified gypsum block

\subsection{Preparation and application of phase change energy storage gypsum block.}

The phase change energy storage material (PCM) was prepared from capric acid (CA) and stearic acid (SA). Through systematic experiment, the PCM (the mass ratio of CA to SA=9:1) was obtained with melting point of $26.8^{\circ} \mathrm{C}$ and latent heat of $126.4 \mathrm{~J} / \mathrm{g}$. The energy storage test were carried out for experiment cubic box (simulating real house) with the addition of PCM in gypsum block $8 \%$ ( based on total solid mass). See Fig.7.

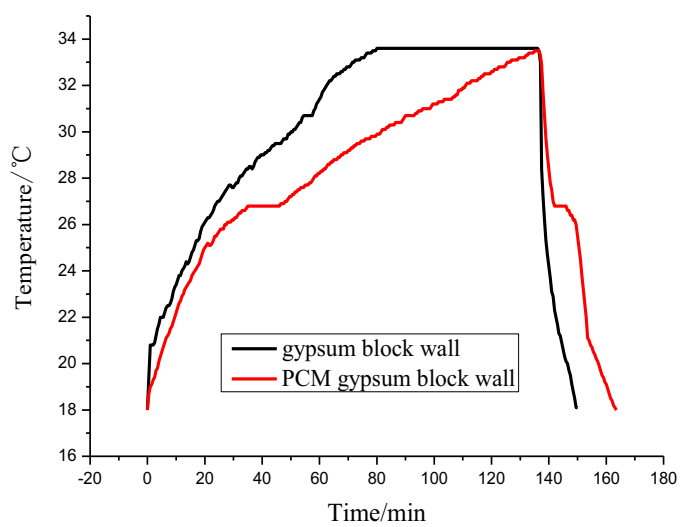

Figure 7. Performance test of PCM gypsum block 
As is shown in Fig.7, the inner surface temperature of PCM gypsum block walls has lagged obviously compared with ordinary gypsum walls, indicating that the phase change energy storage gypsum blocks have good energy storage effect.

\section{Summary}

When SGC powder is used together with gypsum at wet conditions, ettringite and hydrated calcium silicate formed, which is the source of water-resistance of the modified gypsum block. It is proved that WGFP fiber has positive effect on the flexural strength of the block, and the fiber with the length of 10 15 $\mathrm{mm}$ behaves best.

A kind of waste glass fiber-reinforced plastic gypsum block with high strength and excellent water resistance was prepared. The optimal modification formulation is: the content of SGC $25 \%$, WGFP fiber, with the length of $10 \sim 15 \mathrm{~mm}, 1.0 \%$. The product prepared is of softening coefficient of 0.84 , compressive strength of $27.5 \mathrm{MPa}$ and flexural strength of $8.6 \mathrm{MPa}$. It is also shows, compared with ordinary gypsum walls, the modified gypsum block with CA-SA exhibits good energy storage effect.

The block uses large amount of industrial waste material including desulfurization gypsum, steel slag, granulated blast-furnace slag, carbide slag and WGFP fiber. Through this approach, the co-processing of different industrial waste and effective utilization of solid waste are realized.

\section{References}

1. F. Q. Zhao, H. J. Liu, L. X. Hao etc, Water resistant block from desulfurization gypsum, Construction and Building Materials. 27 531-533 (2012).

2. M. M. Zhang, M. M. Chen, et al, Improving Water proof Property of Gypsum Block with Organic-Inorganic Compound Materials, Proceedings of 2nd International Conference on Material Engineering and Application. 707-711 (2015).

3. L. X. Wu, D. Li, Y. X. Chen, Influence of water reducer on performance of cast-in-place wall material with hemi-hydrate desulfurization gypsum, Raliway Engineering. 8 123-126 (2015).

4. K. Deng, J. X. Liu, K. Tu, et al, Analysis of physical and chemical properties of steel slag cementitious materials with inorganic fibers, Multipurpose Utilization of Mineral Resources. 01 73-80 (2015).

5. Y. Cao, G. Z. Li, J. Q. Li, Research on water resistance of glass fiber/gypsum composites, Journal of Wuhan University of Technology. 7 42-46 (2007).

6. X. Q. Ren, F. Q. Zhao, Waste Mycelium Processing and Resource Utilization, Advanced Materials Research. 746 58-61 (2013).

7. M. M. Chen, M. M. Zhang, F. Q. Zhao, Preparation of Gypsum Retarding Material and Activated Carbon from Waste Mycelium, Key Engineering Materials. 703 297-300 (2016). 